\title{
Who Bikes? An Assessment of Leisure and Commuting Bicycling from the Canadian Community Health Survey
}

\author{
Caislin L. Firth ${ }^{1}$ (D), Michael Branion-Calles ${ }^{2}$ (D) Meghan Winters ${ }^{1}$ (D), M. Anne Harris $^{3}$ (D) \\ ${ }^{1}$ Faculty of Health Sciences, Simon Fraser University, ${ }^{2}$ School of Occupational and Public Health, Ryerson University; Department of Emergency Medicine, \\ University of British Columbia, ${ }^{3}$ School of Occupational and Public Health, Ryerson University; Dalla Lana School of Public Health, University of Toronto \\ Keywords: bicycling, leisure bicycling, commute bicycling, bicycling populations, cycling, bike commuting \\ https://doi.org/10.32866/001c.22163
}

We used 2013/2014 Canadian Community Health Survey to describe who bicycles for leisure, commuting, or both leisure and commuting. Nearly onequarter of Canadians bicycled in the 3 months prior to the survey: 7 Canadians bicycled for leisure for every 1 person who bicycled for commuting purposes. People bicycling for leisure were more likely to be younger, male, higher income, and identify as white. Commute bicycling captured a very small proportion of the bicycling population; men were nearly twice as likely to commute compared to women and there was little difference in bike commuting across racial identity.

\section{Questions}

In Canada, primary commute mode to work recorded in census data is one of the few sources to assess bicycling behaviours. Unfortunately, it misses bicycling for leisure and other purposes. The Canadian Community Health Survey (CCHS) - a, nationally representative survey - captures both people who bicycle for non-commuting and leisure as well as for commuting purposes. Our goal is 1) to describe the prevalence of commute bicycling as compared to leisure bicycling and 2) to identify demographic characteristics associated with bicycling for different purposes.

\section{Methods}

We used the CCHS Public Use Microdata Files (PUMF) 2013/2014 cycle; subsequent iterations do not isolate bicycling as an activity. The CCHS sampling frame is Canadians at least 12 years old, but with exclusions (Statistics Canada 2008). Person-level survey weights enable representative estimates across provinces and socio-demographic strata. CCHS assesses bicycling behaviour through the Physical Activity Module, which asks respondents a) whether they bicycled in the past 3 months as a leisure activity or for any purpose not related to work or school, and b) whether they bicycled to and from work or school in the past 3 months.

We calculated the weighted prevalence of three types of bicycling behaviours: people who only engage in leisure and other non-commute bicycling ("leisure only"), people who commute to work or school by bicycle, but do not engage in leisure bicycling ("commute"), and people who do both-leisure and commute bicycling ("leisure + commute"). To identify demographic characteristics associated with different bicycling behaviours, we calculated the prevalence by age, gender, racial identity, and quintiles of household income (adjusted for household and community size). Because the CCHS PUMF 
reports income data for people living in provinces only, our analysis excludes the 110,000 people, or $0.4 \%$ of the Canadian population, who live in territories. Further, racial identity was missing for 4,174 respondents and excluded from analysis.

Finally, we modelled the likelihood of engaging in bicycling using separate weighted logistic regression models for each type of bicycling behaviour. In each model, the outcome was ' 1 ' for respondents who bicycled at least once in the past 3 months for a given type of bicycling and ' 0 ' for participants who reported none. Covariates were demographic characteristics (age, gender, racial identity, income). We reported odds ratios (OR) and $95 \%$ confidence intervals (CI).

\section{Findings}

Nearly one quarter $(23.3 \%)$ of the $28,887,405$ Canadians represented in the 2013/2014 CCHS survey reported bicycling for leisure, and/or to get to work or school in the previous 3 months (Table 1). Most report leisure only bicycling (19.9\% of the population, or $85.6 \%$ of those who reported any bicycling). Only $2.7 \%$ of the population report leisure + commute bicycling, or $11.4 \%$ of those who report any bicycling, and $0.7 \%$ of the population report only commuting, or $3.0 \%$ of those who report any bicycling. People who bicycle for both leisure and commuting take twice as many trips as people who ride for commuting only (52 and 25 trips in the past 3 months, respectively). People who only bicycle for leisure report the fewest number of trips, 16 trips in the past 3 months (Table 1). Population prevalence of any type of bicycle use was highest among people who are men, 20 to 29 years old, identifying as white, with higher household incomes (income quartile 4 and 5) (Table 1).

The multivariable models highlight the demographic differences in who bicycles for each purpose (Table 2). Men were more likely to bicycle than women across all purposes. The disparity was greatest for commute, where men were about twice as likely as women to bicycle for commute (OR: 2.06, CI: 1.45,2.92), or leisure + commute (OR: 1.95, CI: 1.67,2.28), while the disparity was less for leisure-only bicycling (OR: 1.40, CI: 1.32,1.48). Adults over the age of 30 were less likely to bicycle for any purpose. Relative to 20 to 29 year-old bicycle users, those aged 12 to 14 years old were 2.56 times as likely to leisure bicycle only (OR: 2.56, CI: 2.28,2.88) and 75\% more likely to bicycle for leisure + commute (OR: $1.75, \mathrm{CI}: 1.42,2.17)$. Those 15 to 19 years old were more likely to leisure only (OR: 1.75 , CI: $1.57,1.94$ ), leisure + commute (OR: 1.40, CI:1.14,1.71), or commute only (OR: 1.65, CI: 1.07,2.54). 
Table 1: Bicycling behaviour by type and demographic characteristics in Canada, using 2013/2014 Canadian
Community Health with survev weights**

Community Health with survey weights..

\begin{tabular}{|c|c|c|c|c|c|c|c|c|}
\hline \multirow[b]{2}{*}{ Characteristics } & \multicolumn{2}{|c|}{ Leisure bicycling only } & \multicolumn{2}{|c|}{ Both leisure and commuting bicycling } & \multicolumn{2}{|c|}{ Commute bicycling only } & \multicolumn{2}{|c|}{ No bicycling } \\
\hline & N & $\%(95 \% \mathrm{Cl})$ & N & $\%(95 \% \mathrm{Cl})$ & $N$ & $\%(95 \% \mathrm{Cl})$ & N & $\%(95 \% \mathrm{Cl})$ \\
\hline Total & $5,757,383$ & $19.9(19.5,20.4)$ & 767,065 & $2.7(2.5,2.8)$ & 204,840 & $0.7(0.6,0.8)$ & $22,158,118$ & $76.7(76.2,77.2)$ \\
\hline \multicolumn{9}{|l|}{ Age (years) } \\
\hline 12 to 14 & 439,316 & $7.6(7.1,8.2)$ & 80,443 & $10.5(9.0,12.0)$ & 10,212 & $5.0(3.1,6.9)$ & 515,772 & $2.3(2.2,2.5)$ \\
\hline 15 to 19 & 674,130 & $11.7(11.0,12.4)$ & 125,871 & $16.4(14.4,18.5)$ & 36,292 & $17.7(12.5,22.9)$ & $1,186,379$ & $5.4(5.1,5.6)$ \\
\hline 20 to 29 & $1,060,198$ & $18.4(17.4,19.4)$ & 211,088 & $27.5(24.2,30.8)$ & 51,019 & $24.9(18.5,31.3)$ & $3,331,825$ & $15(14.6,15.5)$ \\
\hline 30 to 39 & 931,684 & $16.2(15.3,17.1)$ & 133,718 & $17.4(14.9,20.0)$ & 43,880 & $21.4(14.2,28.6)$ & $3,327,534$ & $15(14.5,15.5)$ \\
\hline 40 to 49 & $1,016,561$ & $17.7(16.6,18.7)$ & 102,920 & $13.4(10.9,15.9)$ & 37,044 & $18.1(11.0,25.2)$ & $3,419,829$ & $15.4(14.9,16)$ \\
\hline 50 to 59 & 900,920 & $15.6(14.6,16.7)$ & 89,655 & $11.7(9.0,14.4)$ & 18,103 & $8.8(5.7,12.0)$ & $4,081,528$ & $18.4(17.9,18.9)$ \\
\hline 60 to 64 & 302,105 & $5.2(4.8,5.7)$ & 17,425 & $2.3(1.4,3.1)$ & 5,932 & $2.9(1.4,4.4)$ & $1,771,234$ & $8.0(7.7,8.3)$ \\
\hline $65+$ & 432,470 & $7.5(7.0,8.0)$ & 5,945 & $0.8(0.4,1.1)$ & 2,357 & $1.2(0.4,1.9)$ & $4,524,017$ & $20.4(20.0,20.8)$ \\
\hline \multicolumn{9}{|l|}{ Gender $^{1}$} \\
\hline Women & $2,477,386$ & $43(41.8,44.3)$ & 256,722 & $33.5(30.4,36.6)$ & 67,093 & $32.8(25.5,40.0)$ & $11,836,229$ & $53.4(52.8,54.0)$ \\
\hline Men & $3,279,996$ & $57(55.7,58.2)$ & 510,343 & $66.5(63.4,69.6)$ & 137,747 & $67.2(60.0,74.5)$ & $10,321,889$ & $46.6(46.0,47.2)$ \\
\hline \multicolumn{9}{|l|}{ Racial identity ${ }^{2}$} \\
\hline White & $4,630,296$ & $80.4(79.4,81.5)$ & 610,866 & $79.6(76.5,82.7)$ & 152,658 & $74.5(66.9,82.1)$ & $16,611,873$ & $75.0(74.3,75.6)$ \\
\hline BIPOC & $1,127,086$ & $19.6(18.5,20.6)$ & 156,199 & $20.4(17.3,23.5)$ & 52,182 & $25.5(17.9,33.1)$ & $5,546,245$ & $25.0(24.4,25.7)$ \\
\hline \multicolumn{9}{|c|}{ Adjusted Income Quintile } \\
\hline Q1 (Low) & 831,955 & $14.5(13.5,15.4)$ & 139,495 & $18.2(15.1,21.3)$ & 44,683 & $21.8(14.6,29)$ & $4,553,317$ & $20.5(20.0,21.1)$ \\
\hline Q2 & 872,971 & $15.2(14.3,16.0)$ & 144,024 & $18.8(16.1,21.5)$ & 38,446 & $18.8(13.0,24.5)$ & $4,631,941$ & $20.9(20.4,21.4)$ \\
\hline Q3 & $1,177,367$ & $20.4(19.4,21.5)$ & 138,847 & $18.1(15.4,20.8)$ & 33,728 & $16.5(11.4,21.5)$ & $4,535,892$ & $20.5(20.0,21.0)$ \\
\hline Q4 & $1,360,289$ & $23.6(22.6,24.7)$ & 167,417 & $21.8(19.2,24.4)$ & 53,452 & $26.1(19.2,33.0)$ & $4,265,911$ & $19.3(18.8,19.7)$ \\
\hline \multirow[t]{2}{*}{ Q5 (high) } & $1,514,800$ & $26.3(25.2,27.4)$ & 177,283 & $23.1(20.4,25.8)$ & 34,530 & $16.9(11.6,22.1)$ & $4,171,058$ & $18.8(18.4,19.3)$ \\
\hline & Sum & Mean $(95 \% \mathrm{Cl})$ & Sum & Mean $(95 \% \mathrm{Cl})$ & Sum & Mean $(95 \% \mathrm{Cl})$ & Sum & Mean $(95 \% \mathrm{Cl})$ \\
\hline \# of trips & $92,806,602$ & $16.1(15.6,16.6)$ & $39,937,874$ & $52.1(48.9,55.3)$ & $5,201,786$ & $25.4(21.3,29.5)$ & $n / a$ & $\mathrm{n} / \mathrm{a}$ \\
\hline
\end{tabular}

${ }^{*}$ Results are reported as population weighted counts $(N)$ and column percentages within each characteristic and bicycle type.

${ }^{1} \mathrm{CCHS}$ collects "sex", without information on non-binary gender.

${ }^{2}$ The CCHS PUMF collapses racial identity to "white" or "visible minority" 
Table 2: Survey weighted logistic regression results for three different models of bicycling participation in the previous 3 months including: 1) leisure bicycling only, 2) both leisure and work or school bike commuting, and 3) work or school bike commuting only.

\begin{tabular}{|c|c|c|c|c|}
\hline & & $\begin{array}{l}\text { Leisure bicycling } \\
\text { only }\end{array}$ & $\begin{array}{l}\text { Both leisure and commute } \\
\text { bicycling }\end{array}$ & $\begin{array}{c}\text { Commute bicycling } \\
\text { only }\end{array}$ \\
\hline & & OR (95\% Cl) & OR (95\% Cl) & OR $(95 \% \mathrm{Cl})$ \\
\hline \multirow{8}{*}{ Age } & 12 to 14 years & $2.56(2.28,2.88)$ & $1.75(1.42,2.17)$ & $0.89(0.55,1.43)$ \\
\hline & 15 to 19 years & $1.75(1.57,1.94)$ & $1.40(1.14,1.71)$ & $1.65(1.07,2.54)$ \\
\hline & 20 to 29 years & Reference & & \\
\hline & 30 to 39 years & $0.87(0.79,0.96)$ & $0.65(0.52,0.82)$ & $0.90(0.55,1.48)$ \\
\hline & 40 to 49 years & $0.90(0.81,1.00)$ & $0.48(0.38,0.62)$ & $0.74(0.43,1.26)$ \\
\hline & 50 to 59 years & $0.65(0.58,0.72)$ & $0.38(0.28,0.50)$ & $0.32(0.20,0.51)$ \\
\hline & 60 to 64 years & $0.52(0.46,0.58)$ & $0.18(0.12,0.26)$ & $0.26(0.14,0.46)$ \\
\hline & $65+$ & $0.32(0.29,0.36)$ & $0.03(0.02,0.04)$ & $0.04(0.02,0.09)$ \\
\hline \multirow{2}{*}{ Gender $^{1}$} & Women & Reference & & \\
\hline & Men & $1.40(1.32,1.48)$ & $2.01(1.74,2.32)$ & $2.06(1.48,2.88)$ \\
\hline \multirow{2}{*}{$\begin{array}{c}\text { Racial } \\
\text { Identity } 2\end{array}$} & White & Reference & & \\
\hline & BIPOC & $0.68(0.63,0.74)$ & $0.62(0.50,0.75)$ & $0.80(0.55,1.17)$ \\
\hline \multirow{5}{*}{$\begin{array}{l}\text { Income } \\
\text { Quintile }\end{array}$} & Q1 & Reference & & \\
\hline & Q2 & $1.04(0.94,1.16)$ & $1.04(0.80,1.34)$ & $0.87(0.52,1.47)$ \\
\hline & Q3 & $1.32(1.19,1.46)$ & $0.85(0.65,1.11)$ & $0.66(0.40,1.1)$ \\
\hline & Q4 & $1.53(1.38,1.69)$ & $0.96(0.76,1.23)$ & $0.99(0.60,1.64)$ \\
\hline & Q5 & $1.74(1.57,1.92)$ & $1.03(0.80,1.31)$ & $0.64(0.38,1.06)$ \\
\hline
\end{tabular}

${ }^{1}$ CCHS collects "sex", without information on non-binary gender.

${ }^{2}$ The CCHS PUMF collapses racial identity to "white" or "visible minority".

An inverse relation between race and bicycling was not statistically significant for commute only (OR: 0.80 , CI: $0.54,1.17$ ), but was significant for bicycling for other purposes. Black, Indigenous, and People of Color (BIPOC) were $32 \%$ less likely to bicycle for leisure only (OR: 0.68, CI: 0.63,0.74) and 38\% less likely to engage in bicycle for both commuter and leisure (OR: 0.62, CI: $0.50,0.75)$. The lack of racial diversity in leisure bicycling has been well documented in Canada and US (Hansen-Gillis 2020; Matthew 2016; Butler 2020). Advocates have called upon the cycling industry and city planners to address barriers to cycling and build safe and inclusive spaces for all people to have opportunities to cycle (Butler 2020; McGowan 2020).

While no clear pattern emerged for commute-related bicycling by household income, there was a pattern observed with leisure-only bicycling: people in the highest income quintiles were $74 \%$ more likely to leisure bicycle compared to people in the lowest income quintile (OR: 1.74, CI: 1.57,1.92) (Table 2).

Leisure is by far the most common reason for bicycling in Canada; there are 7 Canadians who bicycled for leisure for every 1 person that use their bicycle for commuting purposes. There are differences in who cycles for which purposes (leisure versus commute). This analysis of national data shows that people who bicycle for leisure were younger, male, and people who identify as white and have higher incomes. Commute bicycling captures only a very small 
proportion of the population. Men were nearly twice as likely to use their bicycle for commuting purposes as compared to women, and there was a lower prevalence of commuting among BIPOC compared to whites, albeit this difference was not statistically significant. There are some caveats with using CCHS to characterize bicycling behaviour across Canadian populations. For instance, CCHS excludes on-reserve populations from their sampling frame. Better data sources are needed to capture bicycling among rural, remote, and Indigenous populations in Canada.

Census data provide finer geographic resolution than CCHS, but only count the number of people who use a bicycle as their main mode for commuting. We see here that only counting commute bicycling misses the majority of people who bicycle in Canada, and in particular women and younger cyclists. We note that the data used in this analysis are 7 years old, but are the most recent data available, given that the CCHS dropped bicycling questions following the 2013/14 cycle. Research is needed that incorporates data on bicycling purposes, and high geographic resolution census data to generate more accurate and small area estimates of bicycling. In addition to re-instating bicycling questions on the CCHS, Canada needs a national population-based household travel survey (Branion-Calles et al. 2021).

\section{Acknowledgments}

Data for this study were collected by Statistics Canada and made available through Statistics Canada's Data Liberation Initiative. CF and MW were supported by the Canadian Institutes of Health Research (CIHR) for Environments and Health: Intersectoral Prevention Research. MW was supported by a Michael Smith Foundation for Health Research Scholar Award. A CIHR operating grant held by MAH contributed salary support for MBC. 


\section{REFERENCES}

Branion-Calles, Michael, Kay Teschke, Mieke Koehoorn, Osvaldo Espin-Garcia, and M. Anne Harris. 2021. "Estimating Walking and Bicycling in Canada and Their Road Collision Fatality Risks: The Need for a National Household Travel Survey.” Preventive Medicine Reports, June. https://doi.org/10.1016/j.pmedr.2021.101366.

Butler, Tamika. 2020. "Why We Must Talk About Race When We Talk About Bikes.” Bicycling, 2020.

Hansen-Gillis, Lily. 2020. "Opinion: White Cyclists, We Must Do Better." Canadian Cycling Magazine, 2020.

Matthew, D.C. 2016. "Why Are so Few Black People Cycling in Toronto?” Now Magazine, 2016. https://nowtoronto.com/why-are-so-few-black-people-cycling-in-toronto.

McGowan, Ayesha. 2020. "How We Can Build an Anti-Racist Outdoor Industry." Outside, 2020.

Statistics Canada. 2008. "Canadian Community Health Survey - Annual Component (CCHS)." 2008. 